\section{Actualidades en el mundo de la neumología y la cirugía torácica}

\section{Contenido}

- Especial situación de la influenza en México

- Noticias internacionales

\section{ESPECIAL SITUACIÓN DE LA INFLUENZA EN MÉXICO}

La influenza nos afecta cada año y requiere una atención permanente. Ocasiona en todos los países enfermedad y muerte, siendo prevenible con vacunación. Año con año genera enfermos con falla respiratoria que requieren cuidados especializados, frecuentemente a cargo de los neumólogos e intensivistas. Por lo mismo, es de interés primordial para la especialidad y un tema que debe abordarse en el entrenamiento de los residentes médicos, del personal de salud interesado en la atención respiratoria, y en la educación continua de todos ellos. Sería deseable que se ofreciera en esta sección información actualizada sobre la influenza en el mundo y en Latinoamérica, y que aun en caso de no existir estadísticas oficiales de un país, los miembros pudieran ofrecer registros hospitalarios, que si se hacen de manera adecuada pueden ser más certeros y rápidos que las estadísticas habituales de salud, que aparecen con un retraso considerable. Siendo una enfermedad prevenible por vacunación, es inaceptable que mueran personas por influenza, y que exista un rechazo a proveerla en proporciones adecuadas y recibirla, inclusive por el personal de salud.

Registro sindromático de pacientes con enfermedad semejante a influenza: Éste se da con diagnósticos sindromáticos provenientes de hospitales o centros de salud, como el que se ofrece por parte del Instituto Nacional de Enfermedades Respiratorias Ismael Cosío Villegas de la Ciudad de México. Es un registro de consultas, pacientes hospitalizados e intubados por neumonía asociada a síndrome de influenza, que responde rápidamente a la temporada de influenza y que posteriormente se completa con registros de virus respiratorios. Una similar aparece en la página de la CDC, proveniente de un grupo de centros centinela. Esta información es relativamente fácil de recolectar sistemáticamente en otras instituciones de salud.

Ausentismo escolar: El ausentismo es otro registro potencial que puede ir al día y puede detectar de manera temprana brotes de influenza en las escuelas.

Registros de virus respiratorios circulantes: Es importante para detectar los virus y microorganismos causantes de infecciones respiratorias y, en el caso de la influenza, ser capaces de detectar variantes virales o virus con potenciales pandémicos.

Casos y decesos con influenza confirmada por laboratorio: Se utiliza frecuentemente, como por ejemplo, en los registros de la OMS durante la pandemia; pero es conocido que subestima considerablemente los enfermos y los muertos dependiendo de la proporción de pacientes a los cuales se les realizó una prueba de influenza en condiciones óptimas. En la reciente pandemia de 2009, se estimó que el número de decesos fue 15 veces mayor en el mundo y 7 veces mayor en México a las cifras reportadas por la OMS y por la Secretaría de Salud, respectivamente.

Defunciones en la temporada de influenza: Es la medida tradicional y más confiable del impacto en mortalidad de la influenza, que desafortunadamente se puede obtener ya que se recolecta la infor- mación de mortalidad y se compara con la esperada para la temporada. Dependiendo de la rapidez con que se obtenga la información nacional, se tendrá esta cifra, pero siempre meses o años después del brote.

\section{Información relevante de influenza}

Fuente: Dirección General de Epidemiología (DGE), Secretaría de Salud, México.

- Hasta el 6 de febrero del 2014 se registraron 19,586 sospechosos de influenza, de los cuales se han confirmado mediante resultado de laboratorio 3,437 y 374 defunciones.

- Las 374 defunciones registradas con resultado positivo a influenza se distribuyen por fecha de ocurrencia de la siguiente forma: 73 en la primera semana, 143 en la segunda, 70 en la tercera, 71 en la cuarta semana, 15 en la quinta y 2 en la sexta.

- Los 3,437 casos de influenza registrados en el sistema de vigilancia se distribuyen de la siguiente forma por semana: 352 en la semana 01; 887 en la semana 02; 635 en la semana 03; 927 en la semana 04; 597 en la semana 05 y 39 en la semana 06.

- Al comparar el comportamiento de los casos notificados al Sistema de Notificación Semanal de Casos Nuevos (SUAVE), a la misma fecha de corte de 2013 se observó:

- Decremento del $0.5 \%$ en casos de IRA.

- Incremento del $19.8 \%$ en casos de neumonía y bronconeumonía.

- La proporción de consultas por ETI/ IRAG a nivel nacional en las USMI fue de $3.8 \%$. Las entidades con mayor proporción de consultas por ETI/ IRAG en USMI de influenza fueron: Coahuila, Jalisco, Michoacán, San Luis Potosí y Nuevo León.

- Hasta la semana epidemiológica 6:

- En lo que va del 2014, los grupos etarios que más han enfermado por influenza son: el de 40 a 44 
años, seguido del de 30 a 34 y mayores de 65 años.

- Las entidades con mayor proporción de casos confirmados de influenza durante el 2014 son: Jalisco, San Luis Potosí, Distrito Federal, México y Michoacán, que en conjunto suman el $43.6 \%$ del total de casos confirmados.

- De lo reportado a la fecha durante 2014, los estados con defunciones positivas a influenza son: Jalisco, 51; Baja California, 42; Distrito Federal, 36; México, 26; Hidalgo, 25; Querétaro, 23; San Luis Potosí, 23; Michoacán, 20; Zacatecas, 19; Tlaxcala, 14; Aguascalientes, 13; Guanajuato, 13; Chihuahua, 12; Oaxaca, 12; Sonora, 8; Tamaulipas, 6; Coahuila, 4; Nuevo León, 4; Durango, 3; Guerrero, 3; Morelos, 3; Puebla, 3; Veracruz, 3; Quintana Roo, 2; Campeche, 1; Nayarit, 1; Sinaloa, 1; Tabasco, 1; y Yucatán, 1.

- La RNLSP reporta que durante 2014 se observa mayor circulación de los siguientes subtipos virales, presentando de forma descendente: A (H1N1), A no subtipificado, influenza A, A (H3N2), A (H1) y B.

- En el 2014 se han reportado 19,586 casos de ETI/IRAG; de éstos, 3,437 son positivos a influenza, mismos que se encuentran distribuidos de la siguiente forma: A (H1N1), 2,923; A (H3N2), 176; influenza B, 55; influenza A, 89; influenza A (H1), 4; y A no subtipificado, 190.

- Hasta el momento, el Instituto de Diagnóstico y Referencia Epidemiológicos (InDRE) no ha identificado mutaciones relacionadas con cambios antigénicos ni cambios en la virulencia o patogenicidad del virus de influenza, y no se han identificado resistencias virales de oseltamivir.

- El InDRE forma parte del grupo de trabajo del laboratorio del Global Health Security Action Group (GHSAG) y del Laboratory Response Network (LRN) y reporta a FLuNET (Red Mundial de Vigilancia de Influenza, WHO).

- El InDRE notifica periódicamente a FLuNET.

\section{Influenza, situación en el INER}

La figura 1 muestra la situación de la influenza en el Instituto Nacional de Enfermedades Respiratorias en el período del 23 de abril de 2009 al 7 de febrero de 2014.

Páginas web con información regular sobre la situación actual de la influenza:

- Centro de control de enfermedades de EUA (CDC): http://www.cdc.gov/flu/

- Instituto Nacional de Enfermedades Respiratorias de México: http://www.

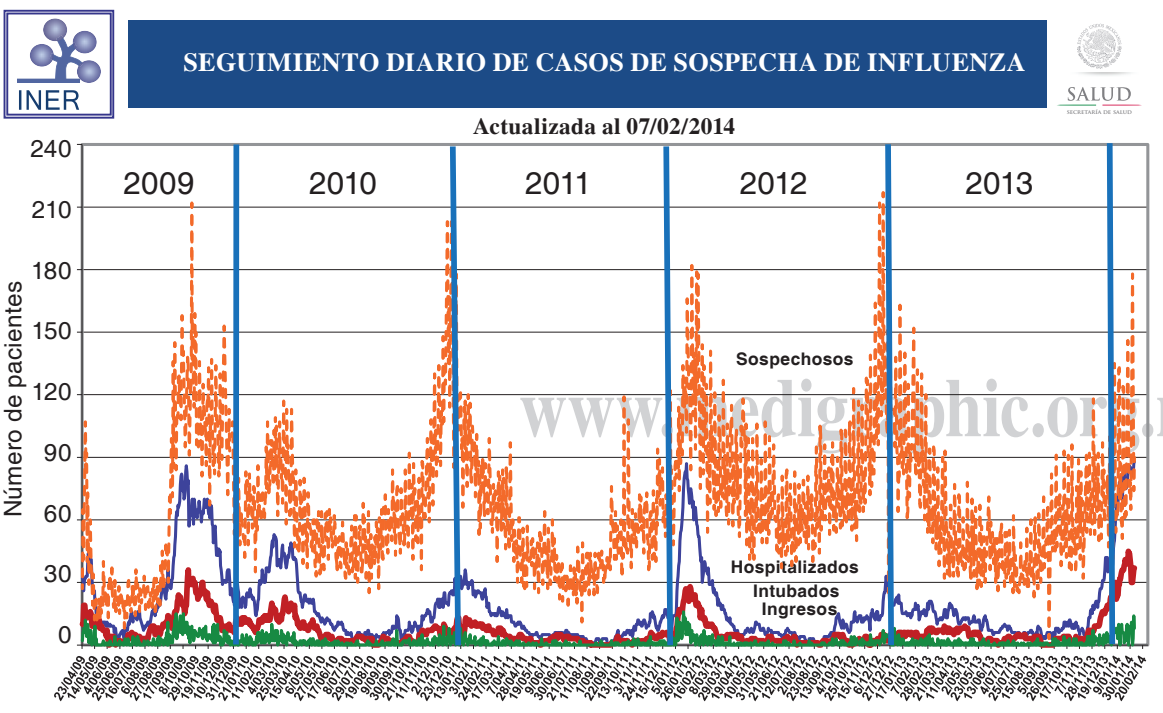

Figura 1. iner.salud.gob.mx/descargas2/informacion_influenza_2014.pdf

- Organización Mundial de la Salud, Europa: http://euroflu.org/

- OMS INFLUENZA H7N9: http:// www.who.int/csr/don/en/index.html

\section{Información general sobre la influenza}

- Biblioteca Virtual de la Salud (OMS, OPS, CDC): http://h1n1.influenza. bvsalud.org/php/index.php?lang=es

- INER México: http://www.iner.salud. gob.mx/contenidos/informacion_influenza.html

Para más información sobre los reportes epidemiológicos semanales sobre influenza, consultar la siguiente liga de la Dirección General de Epidemiología de la Secretaría de Salud de México: http://www.epidemiologia.salud.gob. $\mathrm{mx}$ /informes/2014/influenza/influenzasemanas.html

\section{NOTICIAS INTERNACIONALES}

Scientists concerned $H 10 N 8$ could easily transmit among humans

The Wall Street Journal. February 2014 (Burkitt) "China Realtime" blog reports that scientists have expressed concern over a newly emerged influenza strain, H10N8, believing it has now mutated and that humans can carry it.

Bloomberg News. February 2014 (Bennett) reports yesterday Chinese researchers wrote in The Lancet that H10N8 contains similar genes to H9N2, H5N1, and H7N9 strains and "contains a mutation that helps it adapt to mammals, and may enable the virus to become more infectious." According to study leader Yuelong Shu at the Chinese Center for Disease Control and Prevention, "The pandemic potential of this novel virus should not be underestimated. Although we cannot predict whether an H10N8 epidemic will occur, our findings suggest that the virus is a potential threat to people."

Reuters. February 2014 (Kelland) reports that while this particular strain has only infected two known people thus far, scientists believe it still represents a pandemic threat, particularly because 
humans tend to have no prior immunity to viruses that come from animals. Scientists were unable to locate any traces of the virus at the poultry market the now-deceased H10N8 patient visited before demonstrating symptoms, leaving the source unknown.

Medscape. February 2014 (Brown) reports that today, Nanchang City Disease Control and Prevention's HaiYing Chen published an article online in The Lancet stating, "A genetic analysis of the H10N8 virus shows a virus that is distinct from previously reported H10N8 viruses, having evolved some genetic characteristics that may allow it to replicate efficiently in humans." Chen added, "A second case of H10N8 was identified in Jiangxi Province, China, on January 26, 2014. This is of great concern because it reveals that the H10N8 virus has continued to circulate and may cause more human infections in [the] future."

$\triangle$ Correspondencia:

Lic. Gustavo Giraldo Buitrago,

Jefe del Departamento de Relaciones Públicas

y Comunicación Social.

Instituto Nacional de Enfermedades

Respiratorias Ismael Cosío Villegas.

Calzada de Tlalpan 4502, colonia Sección XVI.

México, D.F., 14080.

Correo electrónico: gustavo.giraldo@gmail.com 